\title{
The Improvement of Mathematical Spatial Visualization Ability of Student through Cognitive Conflict
}

\author{
Wati Susilawati ${ }^{\mathrm{a}}$, Didi Suryadi ${ }^{\mathrm{b}}$ \& Jarnawi A. Dahlan ${ }^{\mathrm{b}}$ \\ ${ }^{\text {aS }}$ tate Islamic University of Sunan Gunung Djati Bandung, INDONESIA; \\ ${ }^{b}$ Indonesia University of Education, INDONESIA
}

\begin{abstract}
The relevance of cognitive conflict is the most controversial issue in mathematical geometry which becomes the most difficult unit to teach in all educational levels. Low mastery of geometry subject is not only identified among Indonesian student teachers but also those in some developed countries like the United States. This study investigates: The improvement of spatial visualization ability between students who are exposed to cognitive conflict strategy and those taught by expository seen from: overall student sample, and levels of prior mathematical knowledge. The interaction between learning types and categories of prior mathematical knowledge on the improvement of spatial visualization ability. The difficulties encountered by students in completing spatial visualization questions. This study used a mixed-method of experimental pre and posttest control group design that involved 73 student teachers at university in Bandung Indonesia as samples. Study findings show that: The mathematical spatial visualization ability of students who are exposed to cognitive conflict strategy has higher improvement level than students who are exposed to expiratory teaching based on overall and prior mathematical knowledge. There is an interaction between learning types and prior mathematical knowledge on the improvement of spatial visualization ability, thus students' difficulties in completing the spatial visualization questions can be minimized. Unlike previous studies which claim that cognitive conflict occurs during cooperative collaboration, this study argues that such conflict happens at cooperative exploration stage.
\end{abstract}

KEYWORDS

cognitive conflict strategy, spatial visualization, cooperative collaboration
ARTICLE HISTORY

Received 10 January 2017 Revised 18 March 2017 Accepted 13 April 2017

\section{Introduction}

Geometry is an essential subject that students at teacher college should learn. Evidence shows that almost 40 percents of mathematics topics at school such as algebra, trigonometry, and calculus include geometry. The purpose of

CORRESPONDENCE Wati Susilawati $\square$ wati85@uinsgd.ac.id

(C) 2017 W. Susilawati, D. Suryadi and J. A Dahlan

Open Access terms of the Creative Commons Attribution 4.0 International License

(http://creativecommons.org/licenses/by/4.0/) apply. The license permits unrestricted use, distribution, and

reproduction in any medium, on the condition that users give exact credit to the original author(s) and the source, provide a link to the Creative Commons license, and indicate if they made any changes. 
this inclusion is to develop students' mathematical thinking, logics, and their spatial intuition about real world. In fact, our life is surrounded and shaped by geometry (space and surface) so that the learning and teaching of mathematics should be based on and directed towards understanding the spatial aspects around students' life. In this line, (Lappan, Fey, Fitsgerald, Friel, and Phillips, 2002) argue that the main purpose of learning geometry is to enable students to have good understanding of spatial concepts and procedures encountered in their life so that they have the ability to solve these spatial problems in their real life situation.

Nevertheless, empirical studies on geometry learning and teaching in both Indonesia and international level found that the result of geometry learning is not satisfactory yet, (Swafford, et al., 1997; Ives, 2003; Risma et al., 2013). These studies show that students' low competence of mathematical spatial visualization is due to some reasons; (1) students' inability to visualize threedimensional objects within two-dimensional one. Empirical data show that many students make mistakes in drawing in three dimensions into two dimensional objects or the opposite from two dimensional to in three dimensional objects. (2) lack of creative spatial sensing leading to mistake in spatial visualization meaning, (3) considering spatial pictures as flat ones where intersecting lines are considered parallel, (4) constructing a visual representation in mind, on paper, or using technological devices, two-dimensional into three dimensional objects seen from different points of view without sufficient learning supports.

Actually, the various abovementioned problems can be proportionally handled and minimized by external factors. One of which is by designing learning materials which can develop students' autonomy in class management, media project making, thinking and doing activities relevant with their environment (Henningsen \& Stein 1997; Nohda 2000; as cited in Suryadi, 2012). Students' perceptions on field of study will develop well depending on the tasks or problems they are assigned to solve, believes that students do not develop good understanding about something through repetition but through active learning and meaning making by building past experience trough group work or activity. Furthermore, (Ben-Chaim, et al., 1988 and Nemeth, 2007) state that spatial visualization ability is not a geometry ability which is genetically inherited or a given ability but a competence which should be trained through a long social construction. This ability can only be developed when students are involved in empowering learning activities or face real life experience

Geometry learning is expected to provide students with an attitude or habit of visualizing the relationship between elements and characteristics of geometrical spaces. To achieve this, students should be provided with the opportunity and sufficient supporting learning media so that they can observe, explore, and find out geometrical principles through informal activities before applying what they have informally learned into their formal learning activities. Someone cannot properly differentiate the relationship among elements of spatial objects without the assistance of concrete media, and students who are not equipped with concrete media but rely solely on their visualization ability are prone to misconception. More specifically, (Downs, 2006) states that students can develop their visualization ability by gathering sufficient information. With 
this, they have already had good and comprehensive knowledge on the logic of spatial concept and representation supported by relevant learning media.

The spatial visualization ability can be developed through the use of various learning media which serve as the main tasks assigned to students, including origami, geoboard, mekorama, pop-up book, and geogebra. These media can help students to use their motoric ability as well as to develop spatial visualization process on their mental image. Exercises in mental transformation relate to metacognitive knowledge so that students can answer questions more easily. This also indicates that spatial visualization ability is required by the curriculum and should therefore be accommodated in geometry learning in the classroom. Indicators of spatial visualization ability in this study are:

1. Ability of imagining and illustrating a geometry object after experiencing rotation, reflection, and dillatation.

2. Ability of decing apicture object which is suitable with its certain position of series of spatial geometry objects.

3. Ability of predicting accurately a real form at spatial geometry object perceived in the certain perspective.

4. Ability of deciding simple object picture which is sticked to more complex picture.

5. Ability of constructing a model related to spatial geometry object.

6. Ability of drawing and comparing logical relation of spatial form components.

Consequently, effort made to improve the teaching and learning process is always interesting to study. One strategy which can address students' problems in spatial visualization is cognitive conflict strategy. This inquiry-based learning stimulates students to learn from their assigned tasks, learning materials, and the project of learning media making by constructing their own divergent and contextually-stimulated problems. In turn, these can stimulate students' cognitive conflict and challenge them to explore their projects in the classroom. This study develops knowledge through the task, even nowadays, reparing prospective teachers of mathematics professionals in the future not only relying on the knowledge acquired it self, the involvement of teachers and other as well as completing the task is needed to meet the challenges of the problems. According to (Shaidullina, et al., 2015) the education quality constantly transformed as needed by society which involving student potential development.

Therefore, cognitive conflict strategy is considered as learning method which can answer students' needs to work hard and exploit their thinking when facing a problem which contradicts their cognitive structure. The conflict due to different cognitive structure will finally lead to a shift in understanding so that students can develop a new understanding or knowledge (Lee, et al., 2003).

Cognitive conflict strategy is a learning method which is interactive, inspiring, fun, and challenging. It motivates students to actively participate in thinking process and leaves enough room for the development of their initiative, creativity and independence relevant to their talent, interest, psychological and 
cognitive development. This fact also indicates that learning is inseparable from thinking process which requires problem solution. A study by (Baddock \& Bucat, 2008 and Lam, 2009) show that a learning process is considered meaningful when it can stimulate students' motivation and enthusiasm to come up with a new product or project such as a documentary video which can be used to make a cognitive conflict, a resolution leading to further understanding of a concept, and a multimedia-based learning to uncover new ideas which can decrease cognitive conflict.

Another study by (Pathare \& Pardhan, 2011; as cited in Dahlan 2012) states that one way to reduce misconception is by directly experiencing the problem so that it can cause accommodation disequilibrium as suggested by Piaget's cognitive conflict. An interaction between cognition and environment used to stimulate conflict is also stated by (Hasweh, 1986), which is the conflict between initial or entry concept and new materials to learn. In addition, (Kwon, 1989) also argues that the conflict between new learning material and environment can be explained by initial or entry concept. Meanwhile, Piaget believes that such this conflict can be explained by the concept to be learned. (Hashweh, 1986; Kwon, 1989; Ismaimuja, 2009; as cited in Dahlan 2012).

Piaget (Watson, 2002; Sutawijaya \& Dahlan, 2010; as cited in Dahlan, 2012) claimed that cognitive structure is integrated into environment through assimilation and accommodation. If the assimilation and accommodation are conflict-free, the cognitive structure is in the equilibrium state. But, when someone is in the state disequilibrium, he will respond by searching for a new equilibrium with his environment. To provide a clearer direction of cognitive conflict, Piaget classified it into three levels; low, medium, and high. Low level happens when someone is in equilibrium state with no conflict during accommodation and assimilation. At this level, information is properly assimilated and accommodated into someone's previous knowledge relevant with the schemata in his or her mind. At medium level, a cognitive disequilibrium or conflict occurs when new information cannot be assimilated so that accommodation of the information does not take place. At this stage, a scaffolding is required from teachers or peers who do not experience cognitive conflict. At high level, a re-equilibrium occurs due to information reconceptualization so that a new equilibrium comes but is against the conflict.

As suggested by (Suryadi, 2012) at high level, an equilibrium happens due to intervention or scaffolding deliberately provided by peers or teachers to help support the thinking process so that the assimilation and accommodation can take place properly. It can, therefore, be concluded that cognitive conflict disequilibrium needs to be conditioned to achieve another equilibrium higher than the previous one.

In the context of cognitive conflict strategy, mathematical knowledge tends to be accepted by individuals through challenging tasks which cause conflict. (Filonovich, 2009: as cited in Maron 2016) argues that learning which is based on social construction can create and develop knowledge through tasks or assignments, not merely from teacher's instruction. Let alone in this information era where teacher is not the only source of information. Individual knowledge is heavily reliant on social construction from peers and teachers who help reconstruct new learning concept to overcome conflict. Therefore, sustained 
completion of exercises or tasks is required to meet the challenges resulted from problem.

In addition to the abovementioned empirical evidence, another factor also contributes to spatial visualization ability, that is prior mathematical knowledge, which is categorized into three levels: high, medium, and low. The different categories emerge as the result of various high school backgrounds (islamic, natural science, social science, language, and vocational high school). It then causes varying levels of students' prior mathematical knowledge. Technically, prior mathematical knowledge is purposed of observing the similarity between experiment group and control group and each sample has considerably same degree. Furthermore, the categorization of prior mathematical knowledge is done to study the different treatments towards students in each category during learning.

Clearly, the problems of the research are:

1. Is the improvement of spatial visualization ability in mathematics between students exposed to cognitive conflict strategy higher than that of students exposed to expository learning as seen from overall students?

2. Is the improvement of mathematical spatial visualization ability between students exposed to cognitive conflict strategy higher than that of students exposed to expository learning as seen from prior mathematical knowledge levels (high, medium, low)?

3. Is there any influence interaction between types of learning (cognitive conflict and expository) and types of prior mathematical knowledge levels (high, medium, and low) towards students' spatial visualization ability in mathematics?

4. What are the difficulties found by students in answering mathematical questions demanding spatial visualization?

\section{Research methodology}

This research used an experiment study of pretest and posttest design on two homogenous groups. Randomly chosen, samples were 73 student teachers of medium qualification at a local public religion-based higher education in Bandung, Indonesia. They were categorized into two groups; 35 students of class $\mathrm{B}$ as control group who received individual expository (conventional) and 38 students of class C as experiment group who were exposed to cognitive conflict strategy cooperatively in group. As for the instrument, an initial test was administered to identify students' prior Mathematical Knowledge followed by a pretest and posttest on mathematical spatial visualization ability. Before the instruments were employed, they were validated by experts in mathematics education through content and face validity. The instruments were then revised and tested to analyze the validity, reliability, significance, and level of difficulties. Validation of the content was carried out by considering conformity between the questions and criteria of prior mathematical knowledge aspects, learning materials, and level of difficulties of students. Most importantly, it was validated using spatial visualization ability indicators of students. Data analysis was done through significance test of $\mathrm{t}$-test for normally distributed data (Gaussian), and the Mann-Withney $U$ for test if the data was not Gaussian. 
Meanwhile, to see the interaction between dependent variables, $\mathrm{F}$ test was employed if normality was met; if not, then Adjusted Rank Transform was used.

\section{Results}

The development of learning material in this research is based on a preliminary study on learning problems experienced by students as learners and lecturers as instructors. This study found that the problem faced by students is epistemologically related to their knowledge and concept about geometry, construction and logic. Supporting this, (Duval, 1998) argues that spatial visualization is one of three cognitive processes which can meet the specific epistemological function of geometry, construction and logic. With reference to observation characteristics, it is believed that most students cannot remember in detail the three dimensional geometry formula. Although students are asked to come up with their life experienced problems, the learned concept will not stay long in their long-term memory.

This experiment study started with a test on prior mathematical knowledge administered to two groups of students to identify and distribute students to high, medium, and low levels. Prior mathematical knowledge students in the experimental and control groups have the greatest frequency at medium levels with total 48 people of 73 students. The medium early mathematical ability of students is $65.7 \%$ at sufficient catagory. This distribution indicates that the average prior mathematical knowledge belongs to sufficient or enough. The statistical result of pretest shows that the overall spatial visualization ability of students in both control and experiment groups is relatively similar. The average pretest score of experiment group is 13.29 and that of the control group is 13.57. This average of pretest score indicates that students' prior mathematical knowledge of spatial visualization ability is still very low.

Having introduced cognitive conflict strategy to experiment group, it is identified that the average of their mathematical spatial visualization ability increases significantly. In general, this difference is evidenced from the obtained posttest result. Overall, the average posttest result of experiment group is 73.34 whereas that of the control group is 64.43. Findings also suggest that the improvement of spatial visualization ability of experiment group is also identified from both overall and prior mathematical knowledge categories (high, medium, and low). The experiment group has also obtained more variety of results than the control one. These findings indicate cognitive conflict strategy has good impact against spatial visualization ability. Cognitive conflict strategy provides thus exerting good influence for students in solving problems (Masalimova \& Sabirova, 2014).

In addition to the results of the posttest, the differences in spatial visualization ability are also apparent from the increased ability of students in both groups based on the normalized data gain. Descriptively, the normalized data gain of spatial visualization ability can be explained in Figure 1. 


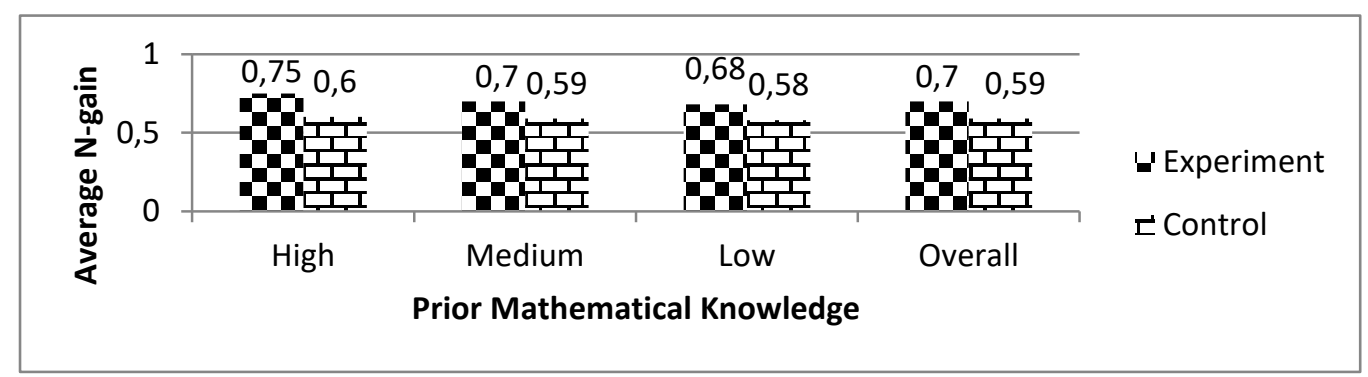

Figure 1. Value $<\mathrm{g}>$ average of spatial visualization between experiment and control groups

As the diagram above shows, the overall average value $<\mathrm{g}>$ of experiment group is 0.70 which belongs to high category, higher than that of the overall average value $<\mathrm{g}>$ of control group of 0.59 which belongs to medium category. Based on prior mathematical knowledge, it is identified that the experiment group has the following $<\mathrm{g}>$ prior mathematical knowledge categories respectively (high, medium, and low) of (0.75, 0.70, and 0.68). Based on this, high and medium on prior mathematical knowledge levels belong to high whereas low on prior mathematical knowledge is included in medium, which is higher than the averages $<\mathrm{g}>$ of control group $(0.60,0.59,0.58)$ which belong to medium category. This difference of improvement indicates that the use of cognitive conflict strategy gives a better contribution to the improvement of students' mathematical spatial visualization ability than the expository learning.

Test of the variance of spatial visualization pretest of both experiment and control groups has the following criteria. $H_{0}$ is accepted if the value sig (1-tailed) $0.973>$ a equals 0.05 . This means that there is no variation in the pretest of spatial visualization ability between experiment and control groups. The test result also indicates that statistically prior to treatment, both experiment and control groups do not have significant difference.

The difference of ability improvement of both groups in variance test of $<\mathrm{g}>$ spatial visualization has the value of $\mathrm{Sig}$ (1-tailed) equals 0.000 and is smaller than 0.05 . so that $H_{0}$ is rejected. This means that students in the experiment group who received cognitive conflict strategy have higher improvement of spatial visualization ability than those in the control group who were exposed to expository learning.

Hence, the cognitive conflict strategy implemented was referring to the theory of (Niaz, 1995 \& Gredler, 1992) that such strategy is able to improve the conceptual change, and lower misunderstanding on the concept by the students. It also raises awareness and proves that it is impossible to have two contradictory views in one situation that each claims for the truth.

Variance test of mathematical spatial visualization ability based on prior mathematical knowledge of high, medium, and low levels respectively have the values of Sig $(0.002,0.000$, and 0.005$)$ smaller than 0.05 so that $H_{0}$ is rejected. This means that students in experiment group have higher improvement of mathematical spatial visualization ability than those in control group. This 
difference of improvement also indicates that cognitive conflict strategy has better contribution in improving students' spatial visualization ability than the expository learning based on prior mathematical knowledge levels (high, medium, and low). The finding suggests the similarity among all categories of prior mathematical knowledge of cognitive conflict strategy group; the students managed to gain benefit from the emergence of conflicts in enhancing their competence.

This result also corresponds to the opinion of (Slavin, 2010) that cognitive elaboration on cooperative learning encourages the improvement of skill of group members. Cognitive conflict strategy, as expressed by Druyan, (2001) will bring up different types of questions related to the influence of cognitive conflict, namely the visual, kinesthetic, and social conflicts between spouses, between children and adults, individual conflicts, as well as peer conflicts. Furthermore, according to (Lee, et al., 2001) the conflicts presented in the strategy of cognitive conflict can be in the form of internal conflicts (the contradiction between two ideas), internal-social conflicts (between two events or information sources), as well as internal-external conflicts (between events or internal and external sources).

Interaction test of prior mathematical knowledge gives a significant influence on spatial visualization ability of value Sig (0.000) which is smaller than 0.05 . For this interaction test, based on prior mathematical knowledge levels and spatial visualization ability learning, it is identified that value sig. (0.007) is smaller than 0.05 so that $H_{0}$ is rejected. This shows that there is an effect of relationship interaction between learning types (cognitive conflict strategy and expository) and prior mathematical knowledge levels (high, medium, and low) on students' mathematical spatial visualization ability. and prior mathematical knowledge (high achieving, medium and low) which influence students' mathematical spatial visualization ability. It shows that the implementation of the challenge-based learning with cognitive conflict strategy needs to pay attention to the students' prior mathematics knowledge (high, medium, and low).

The high prior mathematical knowledge of students has an average of 79.17 , medium with an average of 73.80, and low level with an average of 70.00, while a control group of expository learning has a lower average; high prior mathematical knowledge has an average of 68.75 , medium level by 63.69 , and low level by 60.00 . The difference in such improvement indicates that descriptively cognitive conflict strategy contributes to better improvement of spatial visualization skill on all levels of prior mathematical knowledge, either high, medium and low than that of expository learning.

Spatial visualization ability does not only depend on the students' skill related with initial mathematical knowledge. Indeed, in this study, cognitive conflict strategy are very significant to create the opportunity and encouragement to develop confidence. This is similar with the idea of (Watson, 2002) that conflict cognitive strategies can help students in constructing knowledge from the previous one. (Diezmann \& Watters, 2001; Diezmann, Thornton, \& Watters, 2003) revealed that thinking can expand and enrich the knowledge and support the the involvement of students in completing a challenging task through solving various ill-structured problems. 
Cognitive conflict strategy are an interesting multidisciplinary study, beginning with the giving of assignment based on content standards, allowing the students to work collaboratively in a peer group, and thus become capable of developing the knowledge in completing tasks, identifying and solving the challenges, making differences in their community, and sharing the best deals by enhancing the use of sustainable resources and technology they use in everyday life to solve complex yet contextual misunderstanding. Furthermore, (Kabaca, et al., 2011) revealed that misunderstanding occurs when students acknowledge a gap between new knowledge and the previous one, which should be upgraded through a conceptual change based on cognitive perspective, so that new logical ideas arise. (Battista 1999) indicated spatial ability (including spatial visualisation) as one of the factors that affect success in geometry and geometric problem solving.

The implementation of cognitive conflict strategy in the learning still left some obstacles and difficulties were found among student when doing math tasks using spatial visualization. Problems faced by students in solving spatial visualization questions reveal some indications. First, students' problem in visualizing spatial objects indicates that in solving three-dimensional geometry questions, two dimensional objects are often represented in three dimensions. Second, problems in visualizing two dimensional objects in three dimensions. This means that spatial visualization ability test is relatively new to the students. They may have just learned it or do not have good understanding of it. Third, students find difficulty in differentiating the relationship between elements of spatial objects. Therefore, they need special training on spatial visualization ability on comprehensive construction logic of complex objects.

\section{Conclusion and Recommendations}

Based on the data analysis and interpretation, Cognitive conflicts strategies can provide a new learning atmosphere for students, give effect to their spatial visualization ability ability in mathematics. This is in contrast to expository learning which make the students less active during the study. From the results of the analysis, some conclusions can be drawn up as follows:

First. The overall improvement of mathematical spatial visualization ability between students of high category who received cognitive conflict strategy treatment is higher than those of medium category who were given expository learning.

Second. Based on all three prior mathematical knowledge levels; high, medium, and low, students who received cognitive conflict strategy treatment have higher improvement of mathematical spatial visualization ability than those who were given expository learning.

Third. There is an influence of interaction between learning types (cognitive conflict strategy and expository) and prior mathematical knowledge levels (high, medium, and low) on students' mathematical spatial visualization ability.

Fourth. Students' difficulties encountered in solving spatial visualization questions can be reduced or minimized.

Based on the conclusions, several recommendations are made: 
First. To support the successful implementation of cognitive conflict strategy, it requires more interesting learning materials designed based on contextual issues and this becomes the initial requirement that the students must understand.

Second. It needs to consider making intervention to support optimum efforts of students in achieving actual development.

Third. Cognitive conflict strategy should not be implemented persistently to avoid saturation; indeed, this strategy should be combined with other active learning approaches, methods, and techniques.

\section{Disclosure statement}

No potential conflict of interest was reported by the authors.

\section{Notes on contributors}

Wati Susilawati - State Islamic University of Sunan Gunung Djati Bandung, Indonesia

Prof. Didi Suryadi - Indonesia University of Education, Indonesia.

Dr Jarnawi A. Dahlan - Indonesia University of Education, Indonesia.

\section{References}

Baddock, M., \& Bucat, R. (2008). Effectiveness of a Classroom Chemistry Demonstration using the Cognitive www.ccsenet.org/ies International Education Studies Vol. 8, No. 13; 201577 Conflict Strategy. International Journal of Science Education, 30 (8), 1115-1128.

Battista, M. (1999). Fifth graders' enumeration of cubes in 3D arrays: Conceptual progress in inquiy based classroom. Journal for Research in Mathematics Education, 30(4), 417-448.

Ben-Chaim, David, Glenda Lappan and Richard T. Houang. (1988). The Effect of Instruction on Spatial Visualization Skills of Middle School Boys and Girls. American Educational Research Journal, 25 (1), 51-71.

Dahlan, J. A., dkk. (2012). Implementasi pembelajaran konflik kognitif dalam upaya meningkatkan high order mathematical thinking siswa. Jurnal Pendidikan, 13(2), 65-76.

Diezmann, C. M, Thornton, C, \& Watters, J. (2003). Addressing the needs of exceptional students through problem solving. In F. Lester \& R. Charles (Eds.), Teaching mathematics through problem solving (pp. 169-182). Reston, VA: National Council of Teachers of Mathematics.

Diezmann, C.M, Watters, J. J, \& English, L. D. (2001). Investigations as the basis for mathematical inquiry. Paper presented at the Ninth International Conference on Thinking, Auckland, New Zealand.

Downs, R. M., (2006). Learning to think spatially, Washington D C the National Academic Press.

Druyan, S. (2001). A comparison of four types of cognitive conflict and their effect on cognitive development. International Journal of Behavioral Development, 25 (4), 226-236.

Duval, R. (1998). Geometry from a cognitive point of view, In G. Mammana \& V, Villani (Eds). "Perspectives on the teaching of geometri for the 2 Ist century" (pp. 37-52). Dordrecht. The Netherlands: Kluwer Academic.

Filonovich, S.R. (2009). Life-long learning: consequences for higher education. Education issues, 4, $55-67$.

Gredler, M. E. (1992). Designing and evaluating games and simulations. London: Kogan Page.

Hashweh, M. Z. (1986). Toward an explanation of conceptual change. European Journal of Science Education, 8 (3), 229-249. 
Henningsen, M., \& Stein, M. K. (1997). Mathematical tasks and student cognition: Classroom-based factors that support and inhibit high-level mathematical thinking and reasoning. Journal for Research in Mathematics Education, 28(5), 524-549.

Ismaimuja (2009). Kemampuan berfikir kritis dan kreatif matematis siswa SMP melalui pembelajaran berbasis masalah dengan strategi konflik kognitif. "Disertasi." tidak diterbitkan. Pascasarjana UPI.

Ives, D, (2003). The Development of sevent graders conceptual understanding of geometry and spatial visualization abilities using mathematical representations with dynamic models. "Dissertation." Montclair State University.

Kabaca, T., Karadag, Z., \& Aktumen, M. (2011). Misconception, cognitive conflict and conceptual changes in geometry: A case study with pre-service teachers. Mevlana International Journal of Education (MIJE), 1 (2), 44-55.

Kwon, J. (1989). A cognitive model of conceptual change in science learning. Physics Teaching, 7, 19, Korean Physics Society.

Lam, S., Cheng, R., \& Ma, W. K. (2009) Teacher and student intrinsic motivation inproject-based learning. Instructional Science: International Journal of the Learning Sciences, 37 (6), pp. 565-578.

Lappan, Fey, Fitsgerald, Friel, \& Phillips. (2002). Getting to know connected mathematics. an implementation guide. New Jersey: Prentice Hall.

Lee, G, et al. (2003). Developmentof an instrument for measuring cognitive conflik in secondary-level science classes. Journal of Research in Science Teaching, 40 (6), 585-603.

Lee, G. \& Kwon, J. (2001). What do you know about students' cognitive conflict: A theoretical model of cognitive conflict process. Proceedings of 2001 AETS Annual meeting, Costa Mesa, CA, pp. 309-325.

Maron, A. I. (2016). Priorities of teaching mathematics in universities IEJME International Electronic Journal of Mathematics Education, 11 (9), 3339-3350.

Masalimova, A. R., \& Sabirova, L. L. (2014). Multi-dimensional classification of types and forms of corporate education. American Journal of Applied Sciences, 11, 1054-1058.

Nemeth, B. (2007). Measurement of the development of spatial ability by mental cutting test: "Annales mathematicae et informaticae." (34), 123-128.

Niaz, M. (1995d). Cognitive conflict as a teaching strategy in solving chemistry problems: A dialecticconstructivist perspective. Journal of Research in Science Teaching, 32,959-970.

Nohda, N. (2000). Teaching by Open-Approach Method in Japanese Mathematics Classroom. In: Proceedings of the PME-24 Conference (eds. T. Nakahara \& M. Koyama), Vol.1, 39-53. Hiroshima University (Japan

Pathare, S. R., Pardhan, H. C. (2011). Students' understanding of thermal equilibrium, Proceedings of epi STEME-4. International conference to review research on science, technology and mathematics education, Macmillan publishers India Pvt. Ltd., 169.

Risma, D, A., Putri, R. I., Hartono, Y. (2013). On developing students spatial visualization ability. Journal International Education Studies, 6 (9), ISSN.1913-9020. E-ISSN 1913-9039. Canadian center of science and educations.

Shaidullina, A. R., Evsyukova N. Y., Mikhailov V. A., Gazizova F. S., Masalimova A. R., Khairullina E. R. \& Galimzyanova I. I. (2015). The Curriculum Project on Professional and Pedagogical Teachers' Communication Culture Formation. Mediterranean Journal of Social Sciences, 6(2 S3), 202-208

Slavin, E. Roberts. (2010). Cooperative learning teori, riset, dan praktik cetakan viii. Bandung: Nusa Media.

Suryadi, D. (2012). Membangun budaya baru dalam berpikir matematika. Bandung: Rizqi Press.

Sutawijaya, A. \& Dahlan, J. A. (2010). Model-model pembelajaran matematika. Modul UT: Jakarta. 
Swafford, J. O., Jones, G. A., Thornton, C.A. (1997). Increased knowledge in geometry and instructional practice. Journal for Research in Mathematics Education, 28 (4), pp. $467-483$. Reston : NCTM.

Watson. (2002). Creating cognitive conflict in a-controlled research setting: Sampling. Web: http://www.stat.auckland.ac.nz/ iase/publication/1/6a1_wats.pdf. 